\title{
L IN K
}

http://ejournal.poltekkes-smg.ac.id/ojs/index.php/link

\section{UPAYA PEMULUNG DALAM MENCEGAH RISIKO GANGGUAN KESEHATAN DI TPA BANJARAN KECAMATAN BOJONGSARI KABUPATEN PURBALINGGA TAHUN 2017}

\author{
Dwi Sinar Seppina*) ; Nur Hilal ; Hari Rudijanto IW \\ Jurusan Kesehatan Lingkungan; Poltekkes Kemenkes Semarang \\ Jl.Raya Baturaden KM 12 Purwokerto, Indonesia
}

\begin{abstract}
Abstrak
Tempat Pemrosesan Akhir (TPA) merupakan tempat dimana sampah mencapai tahap terakhir dalam pengelolaannya sejak mulai timbul di sumber, pengumpulan, pemindahan/pengangkutan, pengolahan dan pembuangan. Pemulung ikut serta dalam pengolahan sampah, yaitu memungut benda yang masih dapat dijual. Kegiatan pemulung di TPA berisiko terkena penyakit, karena pemulung di TPA bekerja pada tempat yang kotor. Penelitian ini bertujuan untuk mengetahui upaya pemulung dalam mencegah risiko gangguan kesehatan di TPA Banjaran. Jenis Penelitian yang digunakan adalah deskriptif. Data yang digunakan adalah data umum dan data khusus. Pengambilan data dilakukan dengan cara wawancara dan observasi. Subyek penelitian yaitu 50 orang pemulung di TPA Banjaran. Analisis data dilakukan dengan deskriptif, dengan melihat hasil observasi dan wawancara pada pemulung. Hasil penelitian menunjukkan upaya pemulung dalam mencegah risiko gangguan kesehatan di TPA termasuk katagori kurang baik dengan rincian sebagai berikut, personal hygiene $(76 \%)$, pengetahuan pemulung $(40 \%)$, menghindari vektor binatang pengganggu (46\%), pengobatan (40\%), dan kebugaran jasmani (44\%). Peneliti menyimpulkan upaya pemulung dalam mencegah risiko gangguan kesehatan di TPA masih kurang baik.
\end{abstract}

Kata kunci: risiko gangguan kesehatan ; upaya pemulung

\begin{abstract}
[THE SOLUTION OF SCAVENGERS TO PREVENT HEALTH PROBLEM IN FINAL PROCESSING AREA OF BANJARAN, BOJONGSARI, PURBALINGGA, 2017] Final Processing Place (TPA) is where waste has reached the final stage in its management since it started to arise at source, collection, transport / transportation, processing and disposal. Scavengers participate in the processing of waste, which is picking up objects that can still be sold. Scavengers in final processing sites are at risk of disease, because scavengers in the final processing place work in dirty places. This study aims to determine the scavengers efforts in preventing the risk of health problems in the TPA Banjaran. Research type used is descriptive. The data used are general data and special data. Data collection is done by interview and observation. The research subjects were 50 scavengers at TPA Banjaran. The data analysis was done by descriptive, by looking at observation result and interview on scavenger. The results of the study showed scavengers efforts in preventing the risk of health problems at the final processing site including less good category, the details are as follows, personal hygiene $(76 \%)$, scavenger knowledge $(40 \%)$, avoiding vectors of beasts $(46 \%)$, treatment $(40 \%)$, And physical fitness $(44 \%)$. The researchers concluded that scavengers' efforts in preventing the risk of health problems in the final processing place is less good category.
\end{abstract}

Keywords: risk of health problems, scavengers effort

*) Dwi Sinar Seppina

E-mail: dwisinarseppina201@yahoo.com 


\section{Pendahuluan}

UU No 18 Tahun 2008 tentang Pengelolaan Sampah, disebutkan sampah adalah sisa kegiatan sehari hari manusia atau proses alam yang berbentuk padat atau semi padat berupa zat organik atau anorganik bersifat dapat terurai atau tidak dapat terurai yang dianggap sudah tidak berguna lagi dan dibuang ke lingkungan. Bertambahnya sampah erat kaitannya dengan peningkatan aktivitas manusia dan pertambahan penduduk serta keanekaragaman kehidupan manusia. Sampah yang merupakan bagian sisa aktifitas manusia perlu dikelola dengan baik agar tidak menimbulkan berbagai permasalahan terhadap kehidupan manusia maupun gangguan pada lingkungan, maka sampah yang sudah menumpuk di Tempat Penampungan Sampah harus segera diangkut ke Tempat Pemrosesan Akhir.

Tempat pemrosesan akhir adalah tempat untuk memroses dan mengembalikan sampah ke media lingkungan secara aman bagi manusia dan lingkungan (UU No. 18 tentang Pengelolaan Sampah). Kegiatan yang dilakukan di tempat pemrosesan akhir adalah penerimaan sampah di pos pengendalian, ditempat ini sampah diperiksa, dicatat dan diberi informasi mengenai lokasi pembongkaran oleh petugas. Pengangkutan sampah dari pos penerimaan ke lokasi sel yang dioperasikan, dilakukan sesuai rute yang diperintahkan. Pembongkaran sampah dilakukan di titik bongkar yang telah ditentukan dengan manuver kendaraan sesuai petunjuk pengawas. Perataan sampah oleh alat berat dilakukan lapis demi lapis agar tercapai kepadatan optimum yang diinginkan, kemudian sampah ditimbun dengan tanah secara periodik untuk sistem controll landfill. Pemilahan sampah dilakukan oleh para pemulung. Pemulung menunggu truk sampah yang akan membongkar muatan sampah pada titik bongkar yang telah ditentukan, kemudian pemulung mulai memungut sampah yang masih dapat di daur ulang atau masih ada nilai jualnya.

Pemulung adalah orang yang bekerja mengambil barang-barang bekas atau sampah tertentu untuk proses daur ulang (Junaedi, 2007). Pemulung mempunyai jam kerja yang sangat panjang, bahkan tidak mengenal waktu. Pemulung menghabiskan waktunya di Tempat Pemrosesan Akhir, pada pukul 06.00 WIB pemulung sudah pergi ke TPA untuk mencari sampah sampai pukul 12.00 WIB kembali ke gubuk untuk istirahat makan siang, selanjutnya kembali bekerja 13.00-17.00 WIB bahkan ada yang kembali lagi pukul 19.00 WIB dan bekerja sampai malam hingga pagi selama mereka masih merasa sehat dan mempunyai tenaga (Sinaga, 2008).

Penelitian yang dilakukan oleh Puji Wienna Prastiwi (2013) dalam penelitiannya di TPA Penujah, Desa Penujah, Kecamatan Kedungbanteng, Kabupaten Tegal, menyatakan bahwa dari hasil pemeriksaan laboratorium menunjukkan jumlah pemulung dan petugas TPA yang terinfeksi kecacingan, didapatkan hasil pada petugas TPA sebesar $(50 \%)$, sedangkan pada pemulung $(53,33 \%)$.

Purbalingga hanya memiliki 1 buah TPA yang bernama TPA Banjaran. TPA Banjaran terletak di Desa Banjaran, Kecamatan Bojongsari, Kabupaten Purbalingga. Sistem pengolahan sampah di TPA Banjaran menggunakan sistem controll landfill. TPA Banjaran hanya memiliki 9 unit dump truck untuk mengangkut sampah dan 4 unit arm roll truck, selain itu sarana alat berat yang tersedia di TPA Banjaran hanya ada 2 unit bulldozer dan 1 unit exsavator. Menurut data Dinas Pekerjaan Umum Purbalingga, jumlah pemulung yang ada di TPA Banjaran sebanyak 50 orang. Risiko kesehatan dan kecelakaan kerja pemulung sangat tinggi, hal ini terlihat dari pola kerja yang dilakukan oleh pemulung belum sepenuhnya memahami pentingnya alat perlindungan kerja dan alat perlindungan tubuh untuk mengatasi risiko terganggunya kesehatan. Di sisi lain tempat tinggal pemulung hanyalah gubuk yang menyebabkan pemulung pada umumnya rentan terhadap risiko kesehatan (Sinaga, 2008).

Berdasarkan survey pendahuluan, pemulung ketika bekerja kurang menjaga kesehatan dan keselamatan dirinya, antara lain tidak menggunakan sepatu boot, sarung tangan, dan masker. Hal ini dapat menyebabkan timbulnya gangguan kesehatan. Berdasarkan profil Puskesmas Bojongsari tahun 2015 ada 3 penyakit yang sering diderita pemulung, antara lain penyakit gangguan pernafasan menunjukan jumlah $20 \%$, penyakit sistem pencernaan mencapai sekitar $4,27 \%$, dan penyakit kulit atau dematitis mencapai sekitar $2,47 \%$.

\section{Metode}

Jenis penelitian adalah penelitian deskriptif, yaitu untuk mengetahui bagaimana upaya pemulung untuk mencegah risiko gangguan kesehatan di TPA. Waktu Penelitian dengan tahap persiapan sampai penyelesaian dilakukan 
bulan Oktober 2016-Juni 2017. Lokasi penelitian ini di TPA Banjaran, Kecamatan Bojongsari, Kabupaten Purbalingga. Subyek Penelitian yaitu 50 orang pemulung di TPA Banjaran. Cara Pengumpulan Data yaitu peneliti melakukan observasi langsung di TPA Banjaran dan melakukan tanya jawab dengan pemulung. Instrumen Pengumpulan Data berupa kuesioner. Analisis data dilakukan dengan deskriptif, dengan melihat hasil observasi dan wawancara kepada pemulung. Hasil observasi dan wawancara disajikan dalam bentuk tabel kemudian ditabulasi dan dinarasikan.

\section{Hasil dan Pembahasan}

\section{Risiko Gangguan Kesehatan}

Berdasarkan hasil penelitian, menunjukkan risiko gangguan kesehatan yang paling banyak yang pernah dialami oleh pemulung adalah gatal pada kulit sebanyak 26 orang (52\%), nyeri sendi dalam 3 bulan terakhir sebanyak 26 orang (52\%) dan nyeri otot dalam 3 bulan terakhir sebanyak 26 orang (52\%).

Penyakit gatal pada kulit dapat terjadi karena tumpukan sampah yang merupakan tempat yang baik bagi pertumbuhan jamur. Selain itu dalam bekerja pemulung tidak menggunakan alat pelindung diri yang sesuai, seperti sarung tangan yang terbuat dari karet, dan sepatu boot. Alat pelindung diri ini harus dijaga kebersihannya, hal ini dapat menyebabkan timbulnya penyakit gatal pada kulit. Penyakit gatal pada kulit ini timbul salah satunya karena fakor dari kebersihan diri pemulung itu sendiri (Harahap, 1990).

Pemulung di TPA Banjaran dalam bekerja masih ada yang memakai baju lengan pendek, celana pendek dan tidak menggunakan sepatu boot dan sarung tangan, sehingga tangan dan kaki pemulung tidak terlindungi dan kontak langsung dengan sampah, pemulung juga terpapar sampah setiap hari. Penggunaan APD dan menjaga kebersihan diri (personal hygiene). Penggunaan APD adalah usaha untuk menggunakan alat selama menjalankan pekerjaan sesuai dengan kriteria pekerjaan masing-masing dengan maksud dan tujuan untuk melindungi pekerja agar selama bekerja mendapat kenyamanan dan keselamatan. Kebersihan diri merupakan usaha dari individu atau kelompok dalam menjaga kesehatan melalui kebersihan individu dengan cara mengendalikan kondisi lingkungan (Depkes RI, 2006).
Risiko gangguan kesehatan berikutnya yang dialami pemulung adalah keluhan nyeri sendi dan nyeri otot pada pemulung. Muskuloskeletal disorder (MSDs) adalah gangguan pada bagian otot skeletal yang disebabkan oleh karena otot menerima beban statis secara berulang dan terus menerus dalam jangka waktu yang lama dan akan menyebabkan keluhan berupa kerusakan pada sendi, ligamen dan tendon. MSDs merupakan masalah ergonomik yang sering dijumpai ditempat kerja, khususnya yang berhubungan dengan kekuatan dan ketahanan manusia dalam melakukan pekerjaannya. Masalah tersebut lazim dialami para pekerja yang melakukan gerakan yang sama dan berulang secara terus-menerus (Dino Rimantho, 2015).

Keluhan ini disebabkan oleh pemulung mengumpulkan sampah pada keranjang yang dibawa dipunggung dan pada saat mengais sampah pemulung dalam posisi membungkuk yang disebabkan oleh gancu yang mereka pakai ukurannya cukup pendek ( \pm ) setinggi lutut atau sepanjang siku orang dewasa). Lamanya pemulung memikul keranjang sampah dengan beban berat dapat menimbulkan nyeri pada tulang punggung (Juli Soemirat, 2007).

Berdasarkan hasil observasi sering terlihat pemulung mengais sampah yang berada dibawah dengan membungkuk dimana kaki berada posisi lurus tegak (sudut tubuh $90^{\circ}$ ). Posisi ini sangat cepat menyebabkan pinggang menjadi sakit, karena tekanan langsung yang kuat. Terkadang pemulung mengangkat hasil gendongan sampah dengan beban yang berat. Upaya pencegahan nyeri sendi dan nyeri otot yaitu peregangan otot sebelum melakukan pekerjaan pada setiap harinya. Posisi sedikit berlutut saat mengambil barang jangan membungkuk. Mencodongkan punggung saat mengangkat beban (Dino Rimantho).

\section{Pengetahuan Pemulung}

Berdasarkan hasil penelitian, didapatkan hasil jumlah jawaban 'tidak' terbanyak yaitu data pekerjaan pemulung di TPA dapat menyebabkan penyakit diare sebanyak 35 orang $(70 \%)$. Pendidikan adalah suatu konsep guna untuk mencapai suatu tujuan (Perubahan tingkah laku). Perilaku manusia adalah refleksi dari berbagai gejala kejiwaan antara lain tingkat pengetahuan yang dimiliki seseorang. Tahap pendidikan sangat menentukan kemampuan seseorang dalam mengatasi berbagai masalah 
dalam kehidupannya (Sarwono, 2005). Tingkat pendidikan dan pengetahuan pemulung yang rendah pada umumnya sangat berpengaruh terhadap masalah kesehatan. Hal ini disebabkan oleh orang yang belum mempunyai pengetahuan terkadang melakukan kegiatan yang keliru, tetapi orang tersebut tidak menyadari bahwa perilakunya salah. $70 \%$ pemulung di TPA Banjaran beranggapan bahwa pekerjaan sebagai pemulung tidak akan menyebabkan penyakit diare.

Puskesmas Bojongsari pernah mengadakan penyuluhan mengenai risiko gangguan kesehatan yang ada di TPA, tetapi itu hanya sekali dan sudah lama, padahal pemberian pembekalan pengetahuan tentang APD, penyuluhan tentang risiko keselamatan dan kesehatan kerja oleh Dinas Kebersihan, Dinas Kesehatan, KLH ataupun pihak terkait lainnya dapat memberikan pengetahuan bagi pemulung, sehingga dengan adanya komunikasi ini pengetahuan pemulung tidak terbangun hanya oleh pengalaman yang dialami, tetapi dapat dilakukan upaya pencegahan penyakit akibat kerja sejak dari awal. Dengan demikian seharusnya puskesmas mengaktifkan lagi program pembekalan pengetahuan tentang $\mathrm{APD}$ penyuluhan risiko keselamatan dan kesehatan kerja.

\section{Personal Hygiene Pemulung}

Berdasarkan hasil penelitian, didapatkan jumlah orang yang menjawab 'tidak' terbanyak adalah data mengganti pakaian kerja setiap hari sebanyak 27 orang (54\%). Kebersihan itu sendiri sangat dipengaruhi oleh nilai individu dan kebiasaan, jika seseorang sakit, masalah kebersihan biasanya kurang diperhatikan. Hal ini terjadi karena, pemulung menganggap masalah kebersihan adalah masalah sepele, sehingga pemulung jarang mengganti pakaian kerja setiap hari, jika hal tersebut dibiarkan terus dapat mempengaruhi kesehatan. Menurut Tarwoto, (2004) personal hygiene adalah suatu tindakan untuk memelihara kebersihan dan kesehatan seseorang untuk kesejahteraan fisik dan psikis. Pemenuhan personal hygiene diperlukan untuk kenyamanan individu, keamanan, dan kesehatan. Kebutuhan personal hygiene ini diperlukan baik pada orang sehat maupun pada orang sakit.

Pemulung yang jarang mengganti pakaian kerjanya dapat berisiko terkena penyakit gatal pada kulit, karena pakaian pemulung yang dipakai saat bekerja terpapar debu sampah dan terkena keringat terus menerus dan dapat menimbulkan bakteri. Sebaiknya, pemulung mengganti pakaian kerjanya setia hari, untuk menghindari penyakit gatal pada kulit.

Upaya Pemulung dalam Mencegah Risiko Gangguan Kesehatan di TPA.

\section{Menghindari Vektor Binatang Pengganggu}

Berdasarkan hasil penelitian, didapatkan hasil jawaban 'tidak' terbanyak yaitu data menggunakan lotion anti nyamuk agar tidak digigit nyamuk pada saat bekerja, sebanyak 50 orang $(100 \%)$.Penularan penyakit pada manusia melalui vektor penyakit berupa serangga dikenal sebagai arthropodborne disease atau sering disebut juga sebagai vectorborne disease. Penyakit ini merupakan penyakit yang penting dan seringkali bersifat endemis maupun epidemis dan dapat menimbulkan bahaya kematian (Juli Soemirat, 2009).

Cara menghindari vektor nyamuk di TPA yang mudah yaitu menggunakan pakaian lengan panjang pada saat bekerja di TPA dan menggunakan repellent. Repellent adalah bahan/cara untuk mengusir nyamuk. Contohnya bahan kimia penolak nyamuk yang dioleskan ke tubuh manusia (Juli Soemirat, 2009).

Pemulung tidak menggunakan lotion anti nyamuk pada saat akan bekerja, karena tidak terbiasa dan dianggap tidak perlu. Padahal tempat kerja pemulung di TPA merupakan tempat yang kotor, banyak tumpukan sampah dan lembab, dan nyamuk menyukai tempat yang seperti itu.Kurangnya pengetahuan pemulung menyebabkan pemulung menggap nyamuk yang berkembangbiak di TPA menjadi hal yang biasa, padahal nyamuk ini dapat menyebabkan penyakit demam berdarah dengue.

\section{Pengobatan}

Berdasarkan hasil penelitian, data pengobatan jawaban 'ya' sebanyak 20 orang $(40 \%)$ dan jawaban 'tidak' 30 orang $(60 \%)$. Mengacu pada model Health Belifes Model (HBM), persepsi pemulung mengenai sehat dan sakit akan mempengaruhi perilakunya dalam mencari pengobatan. Jika badan sakit dan masih dapat berdiri atau berjalan, maka pemulung tidak perlu untuk tidak bekerja hanya perlu menelan obat yang dibeli dari warung. Pemulung baru 
akan mencari pengobatan jika sakitnya tidak semakin baik, tetapi pemulung akan pergi kepada Manteri kesehatan yang dekat rumahnya dengan tempat tinggal pemulung (Pooya Arash, 2006).

Berkaitan dengan pelayanan kesehatan pemulung juga mengetahui adanya layanan dari puskesmas dan rumah sakit untuk orang-orang seperti pemulung. Ada pemulung yang memiliki kartu jamkesmas yang pemulung dapatkan dari ketua RT masing-masing, tetapi jarang sekali digunakan, alasan pemulung adalah ketidaktahuan pemulung mengenai prosedur menggunakan jaminan kesehatan. Pemulung juga menyatakan bahwa prosedur penggunaan jaminan kesehatan rumit pemulung cenderung tidak bersedia. Selain itu ada kekhawatiran pemulung masih dipungut biaya.

Dinas Kesehatan Purbalingga bekerja sama dengan Puskesmas Bojongsari sebaiknya mengadakan kembali pemeriksaan kesehatan bagi pemulung secara rutin 6 bulan sekali di TPA Banjaran agar kesehatan pemulung dapat di monitor.

\section{Kebugaran Jasmani}

Berdasarkan hasil penelitian, data kebugaran jasmani jawaban 'tidak' terbanyak adalah melakukan gerak badan sebelum bekerja sebanyak 50 orang (100\%). Pemulung tidak melakukan gerak badan dahulu sebelum berangkat kerja, hal ini dapat menyebabkan nyeri pada tulang belakang atau sering disebut sebagai keluhan musculoskeletal. Keadaan ini dapat terjadi, karena pemulung mengumpulkan sampah di keranjang yang dipikul dipunggung dan pada saat mengais sampah pemulung dalam posisi membungkuk yang disebabkan, karena gancu yang mereka pakai ukurannya cukup pendek ( \pm setinggi lutut atau sepanjang siku orang dewasa) (Dino Rimantho, 2015).

Lamanya pemulung membawa keranjang sampah dengan beban berat dapat menimbulkan nyeri pada tulang punggung. Berdasarkan hasil observasi sering terlihat pemulung mengais sampah yang berada dibawah dengan membungkuk dimana kaki berada posisi lurus tegak (sudut tubuh $90^{\circ}$ ). Posisi ini sangat cepat menyebabkan pinggang menjadi sakit, karena tekanan langsung yang kuat. Terkadang pemulung mengangkat hasil gendongan sampah pulungan dengan beban yang berat.

\section{Menggunakan Alat Pelindung Diri}

Berdasarkan hasil menunjukan jawaban 'tidak' terbanyak yaitu menggunakan sarung tangan pada saat bekerja sebanyak 50 orang $(100 \%)$, dan menggunakan penutup hidung (masker) sebanyak 50 orang (100\%). Penggunaan alat pelindung diri adalah suatu kegiatan atau tindakan memakai sarana untuk melindungi diri dari segala macam bahaya yang dapat terjadi setiap saat tanpa diduga. Pemulung di TPA Banjaran tidak menggunakan sarung tangan dengan alasan tidak nyaman saat mengambil sampah dan pemulung tidak menggunakan masker pada saat bekerja dengan alasan untuk bernafas menjadi susah. Menurut Peraturan Menteri Tenaga Kerja dan Transmigrasi Republik Indonesia Nomor Per.08/Men/VII/2010 Tentang Alat Pelindung Diri, pekerja wajib menggunakan Alat Pelindung Diri saat bekerja sesuai dengan risiko yang dapat terjadi di tempat kerja. Pemulung seharusnya lebih mendisiplinkan diri untuk menggunakan alat pelindung diri.

\section{Simpulan dan Saran}

Simpulan :

a. Risiko gangguan kesehatan yang pernah dialami oleh pemulung adalah gatal pada kulit sebanyak 26 orang (52\%), nyeri sendi dalam 3 bulan terakhir sebanyak 26 orang $(52 \%)$ dan nyeri otot dalam 3 bulan terakhir sebanyak 26 orang (52\%).

b. Pengetahuan pemulung terendah dalam mencegah risiko gangguan kesehatan di TPA Banjaran, yaitu pekerjaan pemulung dapat menyebabkan penyakit diare sebanyak 35 orang $(70 \%) .70 \%$ pemulung beranggapan bahwa pekerjaan sebagai pemulung tidak akan menyebabkan penyakit diare.

c. Personal hygiene pemulung terendah dalam mencegah risiko gangguan kesehatan di TPA Banjaran, yaitu mengganti pakaian kerja setiap hari sebanyak 27 orang (54\%). 54\% pemulung beranggapan bahwa kebersihan diri adalah masalah sepele.

d. Upaya pemulung dalam mencegah risiko gangguan kesehatan di TPA termasuk katagori kurang baik dengan rincian sebagai berikut, personal hygiene (76\%), pengetahuan pemulung $(40 \%)$, menghindari vektor binatang pengganggu (46\%), pengobatan $(40 \%)$, kebugaran jasmani $(44 \%)$ dan penggunaan alat pelindung diri $(40 \%)$. 
Saran :

1. Pemulung di TPA Banjaran hendaknya :

a. Dapat mengupayakan perilaku yang sehat dalam rangka pencegahan penyakit, seperti mencuci tangan pakai sabun sebelum dan sesudah makan, mengganti pakaian kerja setiap hari, memakai baju lengan panjang dan celana panjang agar tidak digigit nyamuk.

b. Lebih mendisiplinkan diri untuk memakai alat pelindung diri (APD).

2. Dinas Kesehatan Kabupaten Purbalingga dan Puskesmas Bojongsari hendaknya :

a. Melakukan penyuluhan kepada pemulungtentang kesehatan diri, tentang penyakit yang ditimbulkan akibat bekerja sebagai pemulung di TPA, dan tentang pentingnya pemakaian Alat Pelindung Diri (APD) saat bekerja di TPA.

b. Mengadakan pemeriksaan kesehatan pemulung secara rutin 6 bulan sekali di TPA Banjaran sehingga kesehatan pemulung dapat di monitor.

\section{Daftar Pustaka}

Arif Mansjoer dkk, 2007, Kapita Selekta Kedokteran, Jakarta: MediaAesculapius.

Aziz Alimul Hidayat, 2007, Metode Penelitian Kebidanan Teknik Analisis Data, Jakarta: Salemba Medika

Cecep Dani Sucipto, 2011, Vektor Penyakit Tropis, Yogyakarta: Gosyen Publishing.

Depkes, R.I., 2000. Buku Pedoman Pelaksanaan Program P2 Diare. Jakarta : Ditjen PPM dan PL.

Dinas Pekerjaan Umum, 2016, “Laporan Tahunan Dinas Pekerjaan Umum",Purbalingga: Pemerintah Kabupaten Purbalingga.

2016, Produksi

Sampah Kabupaten Purbalingga Tahun 2015, Purbalingga: Bagian Kebersihan.

Dino Rimantho, 2015, Identifikasi Risiko Kesehatan Dan Keselamatan Kerja Pada Pekerja Pengumpul Sampah Manual Di Jakarta Selatan Tahun 2015, Skripsi, Jakarta, Universitas Pancasila Jakarta.

Djamaluddin Ramlan, 2006, Dasar-Dasar Kesehatan Kerja, Purwokerto :Poltekkes Depkes Semarang

Herlinda, 2010, Persepsi pemulung terhadap Risiko kesehatan dan keselamatan kerja dikaitkan dengan penggunaan Alat pelindung diri (AP) di Tempat penampungan sampah sementara (TPS) Tegallega, Bandung, 2010, Tesis, Depok, fakultas kesehatan masyarakat Program magister Keselamatan dan kesehatan kerja Universitas indoensia Depok

http:/ / pengertian-kebugaranjasmani.html, diaskes 10 Januari 2017

https://id.wikipedia.org/wiki/Asuransi_keseh atan, diaskes 10 Januari 2017

http://www.padmabhuana.com/diare.html, diaskes 10 Januari 2017

Harahap S, Ilmu Penyakit Kulit, EGC, Jakarta, 1990

Juli Soemirat S., 2011, Kesehatan Lingkungan, Yogyakarta: UGM Press.

Julianto, R. Konsentrasi Metana antara LEL dan UEL, Dapat Menyebabkan Ledakan di TPA Sampah. : www.issdp.or.id

Kamaruddin S (2009). Hubungan mencuci tangan dengan infeksi nosokomial RSUD Purwerejo. Medical Journal of Indonesia, 16(3), pp 195-200.

Keputusan Menteri Kesehatan Nomor 424/Menkes/Sk/VI/2006 tentang Pedoman Pengendalian Cacingan, Jakarta: Departemen kesehatan RI.

Ketut Wikantika. 2005. Lembaga Penelitian dan Pengabdian Kepada Masyarakat (LPPM). Departemen Teknik Geodesi dan Geomatika ITB.

Khaerudin, Mahfud Junaedi, dkk., 2007. Kurikulum Tingkat Satuan Pendidikan, Konsep dan Implementasi di Madrasah. Yogyakarta: Nusa Aksara.

Kodoatie, Robert. 2005. Fakultas Teknik Sipil Universitas Diponegoro.

Kus Irianto dan Kusno W. (2004). Gizi dan Pola Hidup Sehat. Bandung: C.V.Yrama Widya.

Laporan Satgas ITB Peduli Leuwigajah. 2005: www. Itb.ac.id.

Martin Darmasetiawan, 2008, Perencanaan Tempat Pembuangan Akhir (TPA), Ekamitra Engineering

Puji Wienna Prastiwi, 2009, Studi Komparasi Kejadian Kecacingan Antara Pemulung Dengan Petugas TPA di TPA Penujah Desa Penujah Kecamatan Kedungbanteng Kabupaten Tegal Tahun 2009, Karya Tulis Ilmiah, Purwokerto, Departemen Kesehatan RI Politeknik Kesehatan Semarang Jurusan Kesehatan Lingkungan Purwokerto 
Puskesmas Bojongsari, 2016, Data Penyakit Tahun 2015, Purbalingga : Dinas Kesehatan Kabupaten Purbalingga

Pooya Arash, dkk, 2006. The Effect of Zinc and Health Belief Model Based Education on Common Cold Prevention in Soldiers. http://www.scipub.org.pdf [diunduh pada 10 Mei 2017]

Sarwono, Sarlito Wirawan. 2005. Teori-teori Psikologi Sosial. Jakarta: PT. RajaGrafindo Persada.

Setyowati Sabella, 2014, Risiko Gangguan Kesehatan Pada Masyarakat Di Sekitar Tempat Pembuangan Akhir (TPA) Sampah Tanjungrejo Kabupaten Kudus Tahun 2014, Skripsi, Semarang, Universitas Negeri Semarang.

Siregar RS, Tantawi Djauhari, 1990. Dermatofitosis di Rumah Tahanan Negara dan Lembaga Pemasyarakatan Sumatera Selatan ; Penelitian Aspek Kebersihan, Kelembaban dan Temperatur. Dexa Medis

Sinaga, 2008, Kajian Model Pengembangan Usaha di Kalangan Pemulung. Paticipation Research. Jakarta, Desember 2008

Slamet, Juli Soemirat. Kesehatan Lingkungan. Gadjah Mada University Press. Yogyakarta, 2007. Grandjean, E., Fitting the Task to the Man, 4 th ed. Taylor \& Francis Inc. London, 1993.

Sony, Tri Bangun L \& Bagong Suyoto, Pemulung Sang Pelopor 3R Sampah, Jakarta, Pidus Zero Waste Indonesia, 2008

Suma'mur P.K, 1996. Hygiene Perusahaan dan Keselamatan Kerja, Jakarta: PT. Toko Gunung Agung

Sumardjoko, 2003. Profil Wanita Pemulung di Surakarta, Jurnal Penelitian Humaniora, Vol.4 No.2, Universitas Muhammadiah Surakarta

Suryani, D. 2008. Dermatosis Akibat Kerja dan Upaya Pencegahannya Pada Pemulung Sampah di LPA Benowo Surabaya (Skripsi). Universitas Airlangga.

Tarwoto \& Wartonah, 2004. Kebutuhan Dasar Manusia dan Proses Keperawatan. Jakarta : Salemba. 2004

Umar 2009. Kebiasaan mencuci tangan dengan infeksi pada anak SDN 34 Pekalongan, Jawa Tengah. Makara Kesehatan, 6(2), pp55-59.

Undang-Undang Republik Indonesia Nomor 18 Tahun 2008 tentang Pengelolaan
Sampah, Jakarta: Direktorat Jenderal Peraturan Perundangundangan. 